\title{
O EXAME CRIMINOLÓGICO COMO MECANISMO DE BIOPOLÍTICA
}

\section{THE CRIMINOLOGICAL EXAMINATION AS BIOPOLITICS MECHANISM}

\author{
${ }^{1}$ Flávia Ávila Penido \\ 2 Jordânia Cláudia de Oliveira Gonçalves
}

\section{RESUMO}

O presente estudo aborda a exigência do exame criminológico como requisito à progressão de regime. Busca-se evidenciar que a referida perícia tem o condão de funcionar como um mecanismo de biopolítica do Estado, enquanto gestor da vida, fundado em uma estratégia política e de poder. Observa-se que o exame criminológico apresenta-se como uma perícia vista como capaz de prever a periculosidade do agente e, portanto, a probabilidade de reincidência. Com o escopo de proteger os interesses sociais e sem observar a alteração legislativa operada pela Lei 10.792/03, restabeleceu-se, através da súmula vinculante número 26 editada pelo Supremo Tribunal Federal em 2009, a facultatividade de requerimento do exame criminológico como um requisito à progressão de regime de forma a evitar que sentenciados que apresentem alto grau de periculosidade sejam reintegrados ao convívio social. Diante deste contexto, passa-se a defender nesta pesquisa que o restabelecimento de um requisito que dificulta o ingresso em regime de liberdade ou semiliberdade faz parte de uma estratégia geral de poder, como um mecanismo de segurança apto a gerir o bem-estar social através de critérios biológicos de seleção dos indesejáveis.

Palavras-chave: Exame criminológico, Biopoder, Biopolítica, Execução penal

\footnotetext{
${ }^{1}$ Mestre em Direito pela Pontifícia Universidade Católica de Minas Gerais - PUC/MG, Belo Horizonte- MG (Brasil). Professora Pontifícia Universidade Católica de Minas Gerais - PUC/MG, Belo Horizonte- MG (Brasil). E-mail: f.avilapenido@gmail.com

${ }^{2}$ Mestre em Direito pela Pontifícia Universidade Católica de Minas Gerais - PUC/MG, Belo Horizonte- MG (Brasil). Professora da Faculdades Unificadas Doctum de Teófilo Otoni - DOCTUM, Minas Gerais (Brasil). E-mail: jordania_cog@hotmail.com
} 


\begin{abstract}
This study addresses the requirement of criminological examination as a prerequisite to progression scheme. The aim is to show that such expertise has the ability to function as a biopolitics mechanism of the state, as manager of life, founded on a political and power strategy. It is observed that the criminological examination appears as a skill seen as able to predict the dangerousness of the agent and, therefore, the likelihood of recurrence. With the aim of protecting corporate interests and without observing the legislative amendment operated by Law 10,792 / 03, was re-established by binding precedent No. 26 issued by the Supreme Court in 2009, the examination of the application facultatividade criminological as a requirement to progression of the scheme to prevent sentenced presenting high degree of danger to be reinstated to social life. Given this context, going to defend this research that restoring a requirement that limits the entrance under the freedom or semi-freedom is part of a general strategy of power, as a security mechanism able to manage the social welfare through biological criteria of unwanted selection.
\end{abstract}

Keywords: Criminological examination, Biopower, Biopolitics, Penal execution 


\section{INTRODUÇÃO}

A presente pesquisa atenta para a exigência do exame criminológico como um requisito à concessão da progressão de regime que acaba funcionando como um mecanismo de biopoder do Estado, no sentido foucaultiano.

Inicialmente, busca-se identificar o objeto do exame criminológico bem como seus objetivos. Verifica-se que se trata de uma perícia que tem por objetivo delinear a personalidade do sentenciado, seu grau de periculosidade e, portanto, os riscos que o seu retorno ao convívio social pode trazer à segurança pública e aos interesses sociais.

Não obstante a alteração legislativa que suprimiu a exigência do exame criminológico, anteriormente prevista na redação original do parágrafo único do artigo 112 da Lei de Execução Penal (LEP), restabeleceu-se a possibilidade de requerimento do exame criminológico - como um requisito facultativo à concessão da progressão de regime - através da súmula vinculante número 26 editada em 2009 pelo Supremo Tribunal Federal (STF).

Diante desse contexto, busca-se demonstrar que a exigência do exame criminológico faz parte de um plano de gestão da vida através dos mecanismos de segurança, uma vez que o poder político é estrategicamente direcionado à neutralização do indesejável, sob o pretexto de se assegurar a segurança e os interesses sociais.

No que toca ao exame criminológico, vê-se que se condiciona o gozo do sistema progressivo de penas à reforma da personalidade do agente, para que este deixe de apresentar um risco à segurança com a cessação da periculosidade.

Assim, condiciona-se a concessão dos benefícios previstos na LEP a um laudo que tem por objeto a periculosidade do agente, portanto, carregado de subjetividade e pautado na culpabilidade do autor. A subjetividade do laudo permite maior ingerência do Estado que pode pautar a concessão ou não do benefício segundo a toada da política pública vigente.

\section{EXAME CRIMINOLÓGICO: DO OBJETO AO OBJETIVO}

O exame criminológico é uma perícia que tem por escopo delinear a personalidade do condenado através de análise psicológica e da avaliação de sua conduta pessoal, demonstrada principalmente através de sua relação familiar e social. Consiste em uma pesquisa de fatores concomitantes ao crime e aos precedentes pessoais e familiares, "físico- 
psíquico, psicológico e sociológico-ambiental, para a obtenção de dados reveladores de sua personalidade e do seu estado perigoso". (OLIVEIRA, 1980, p.111)

O exame criminológico objeto deste estudo é aquele exigido como requisito subjetivo complementar ao bom comportamento carcerário, necessário à progressão de regime. É o exame previsto na redação original do parágrafo único do artigo 112 da Lei de Execução Penal (LEP) ${ }^{1}$ que tem por objetivo avaliar a periculosidade do agente e, portanto, se este está apto a ingressar em um regime de cumprimento de pena mais brando.

Salo de Carvalho, com amparo na lição de Ibrahim Hoenisch, explica como se desenvolve o trabalho dos técnicos encarregados da realização do exame criminológico:

Percebe Hoenisch que o trabalho do perito, principalmente do psicólogo, é fundado na técnica de „reconstituição de vida pregressa ${ }^{e e}$, que, via de regra, vem a confirmar o rótulo de criminoso. Dessa forma, a elaboração dos exames psiquiátricos obedece a um determinismo causal, onde o „nosólogo" não só descreve a doença / delito do paciente / preso, mas também prescreve sua conduta futura. (HOENISCH apud CARVALHO, 2009, p.144)

É possível traçar como objetivo do exame criminológico a avaliação da possibilidade de ressocialização do condenado, de forma a verificar se está apto para se reintegrar ao convívio social sem oferecer risco aos interesses da segurança social. É o que se extrai da redação do item 32 da exposição de motivos da LEP:

\begin{abstract}
A ausência de tal exame [exame criminológico] e de outras cautelas tem permitido a transferência de reclusos para o regime de semi-liberdade ou de prisão-albergue, bem como a concessão de livramento condicional, sem que eles estivessem para tanto preparados, em flagrante desatenção aos interesses da segurança social. (BRASIL, 2003, p.338)
\end{abstract}

Trata-se de uma tentativa de "'auferir' a personalidade da pessoa presa por ocasião da progressão de regime e do livramento condicional, na expectativa de que se possa presumir que a mesma não voltará a delinquir, ou seja, prever uma suposta 'adaptabilidade social' e a

\footnotetext{
1 O exame criminológico originalmente previsto no parágrafo único do artigo 112 da LEP, objeto deste estudo, difere-se das previsões do artigo 8 da LEP e 34 do Código Penal (CP). O primeiro é previsto como um requisito capaz de aferir a periculosidade do agente e, por conseguinte, atestar a possibilidade de progressão para um regime de cumprimento de pena menos rigoroso. Os últimos identificam o referido exame como instrumento para classificação e individualização da pena no início do seu cumprimento. Dessa forma, a Lei de Execução Penal e o Código Penal trazem previsões distintas quanto ao momento de realização do exame criminológico. E, de acordo com o momento de sua realização, é que será possível analisar seus objetivos: se possibilitar a individualização da pena, com a adequação da mesma às características e necessidades de cada preso, ou servir de fundamento para concessão dos benefícios previstos na LEP, como instrumento capaz de prever a reincidência.
} 
consequente redução da reincidência criminal" ${ }^{2}$. (CONSELHO FEDERAL DE PSICOLOGIA, 2006)

É objeto de análise do exame criminológico a avaliação do grau de periculosidade do agente, ou seja, a sua tendência para o crime. Eugênio Raul Zaffaroni dá a essa tendência o nome de “determinação". Segundo o autor, quando se defende que o homem está condicionado a causas de qualquer ordem que o impelem à prática delituosa, está-se considerando "o grau de determinação que tenha o homem para o delito, ou seja, a periculosidade". Nesse sentido, tem-se "o direito penal da periculosidade, para o qual a pena terá como objeto (e também como único limite) a periculosidade". (ZAFFARONI, 2001, p.115)

Afasta-se os critérios objetivos de avaliação do comportamento criminoso já levado a cabo pelo sujeito e passa-se a pautar a deliberação das práticas punitivas com base no risco potencial que aquele sujeito oferta ao meio social. Dito de outra forma, substitui-se o julgamento adstrito ao fato criminoso consumado e inclui-se em pauta o julgamento do autor em sua subjetividade com a pretensão de avaliar o grau de inclinação que o sujeito tem às práticas criminosas.

Acerca desta pretensão de mensurar o risco que alguém oferta ao meio social, Jurandir Freire, citado por Tânia Kolker, afirma ser impossível prever o comportamento humano, justamente por não ser o homem predeterminado:

(...) é impossível prever o comportamento humano como quem prevê a dilatação do metal pelo calor. É impossível controlar a imprevisiblidade dos homens. Para ele, qualquer tentativa neste sentido, só pode estar a serviço de uma mascarada cumplicidade com as razões de Estado. E avaliar uma pessoa segundo seu grau de adaptação às normas sociais não pode ser considerado outra coisa. (FREIRE apud KOLKER, 2009, p.201)

\footnotetext{
2 O Conselho Federal de Psicologia, no ano de 2010, editou a resolução de nº 0009/2010, que regulamenta a atuação do psicólogo no sistema prisional. Especialmente no artigo $4^{\circ}$, vedou "ao psicólogo que atua nos estabelecimentos prisionais realizar exame criminológico e participar de ações e/ou decisões que envolvam práticas de caráter punitivo e disciplinar, bem como documento escrito oriundo da avaliação psicológica com fins de subsidiar decisão judicial durante a execução da pena do sentenciado". (artigo $4^{\circ}$, alínea a, da Resolução 009/2010 do Conselho Federal de Psicologia). Em nota justificou a vedação ao argumento de que "Não é possível concluir o que ocorrerá com aquelas pessoas, considerando apenas as suas características e condições individuais, sem problematizar todo o processo e os elementos oferecidos para a suposta ressocialização ou superação de fatores que o levarão a cometer novos delitos" (CONSELHO FEDERAL DE PSICOLOGIA, 2010) Esclareceu ainda que a prática contribui somente para a rotulação dos sujeitos, sem, contudo, contribuir para soluções dos problemas inerentes ao cárcere e aos seus personagens.
} 
Da análise do objeto do exame criminológico, qual seja, a periculosidade, apontamse críticas à exigência do exame como um requisito à progressão de regime dada a impossibilidade de se mensurar seu objeto, que é a periculosidade. Trata-se de um exame que se propõe a quantificar o grau de periculosidade do agente, e, a partir disso, verificar se o mesmo está apto a retornar ao convívio social, de forma a não oferecer riscos à segurança social. Considerando que o exame volta-se ao risco de se praticar novos crimes, equivale a um instrumento capaz fazer a previsão da ocorrência de uma conduta criminosa ou, ao menos, capaz de aferir a probabilidade de que aconteça.

A Pastoral Carcerária Nacional, em documento enviado ao Congresso Nacional em 2007, intitulado "Repúdio à re-introdução do exame criminológico", aponta justamente a impossibilidade de aferir a periculosidade, que corresponde a uma pretensão de se fazer um juízo de reincidência, como se fosse possível predizer se o apenado vai ou não voltar a delinquir:

\begin{abstract}
A idéia de se medir a periculosidade do preso e realizar um possível prognóstico de reincidência é impossível e completamente ultrapassada a partir das teorias criminológicas modernas. Tal conceito parte das teorias criminológicas clássicas do século XIX baseadas num modelo médico em que crime é tido como uma realidade ontológica, um fato anormal, expressão de uma anomalia física ou psíquica, cabendo aos operadores das agências do sistema penal procurar as causas do crime na figura do apenado (objeto de estudo) e tratá-lo, ou seja, submetê-lo a exames médicopsiquiátricos para que o "criminoso" não volte a cometer crime algum, em outras palavras, cure-se, a fim de que não volte a cometer crimes (prognóstico da reincidência). (PASTORAL CARCERÁRIA, 2007, p.4)
\end{abstract}

O Conselho Nacional de Política Criminal e Penitenciária (CNPCP), através de um parecer $^{3}$ assinado pela Conselheira Valdirene Daufemback (2008, p. 4-8), cita alguns dos inúmeros fatores que podem contribuir para a prática do crime, tais como escolaridade, situação econômica, relações familiares, capacidades desenvolvidas, entre outras. E, diante das inúmeras possibilidades que decorrem do cruzamento desses dados, em diferentes graus,

\footnotetext{
3 Parecer acerca do Projeto de Lei do Senado n 190 de 2007, que tem por objetivo alterar os artigos $6^{\circ}$ e 112 da LEP para tornar o exame criminológico requisito obrigatório à concessão de qualquer benefício próprio da execução penal. A redação proposta é a que segue: "Art. $6^{\circ}$. A classificação será feita por Comissão Técnica de Classificação que elaborará o programa individualizador da pena privativa de liberdade adequada ao condenado ou preso provisório e acompanhará a sua execução, devendo propor à autoridade competente as progressões e regressões dos regimes, bem como as conversões. (NR)" e "Art. 112. A pena privativa de liberdade será executada em forma progressiva, com a transferência para regime menos rigoroso, a ser determinada pelo juiz, quando o preso tiver cumprido ao menos um sexto da pena no regime anterior, e o seu mérito indicar a progressão. Parágrafo único. A decisão sobre progressão de regime, livramento condicional, indulto e comutação de pena será motivada e precedida de parecer da Comissão Técnica de Classificação e do exame criminológico, quando necessário. (NR)". (BRASIL. Projeto de Lei do senado no 190 de 2007. Altera a Lei nº 7.210, de 11 de julho de 1984, para prever o exame criminológico para progressão de regime, livramento condicional, indulto e comutação de pena. Disponível em: 〈http://legis.senado.gov.br/mate-pdf/9748.pdf> Acesso em: 21 jul. 2015).
}

Revista de Criminologias e Políticas Criminais | e-ISSN: 2526-0065 | Minas Gerais | v. 1 | n. 2 | p. 40 - 56 | Jul/Dez. 2015. 
não seria possível precisar a possibilidade da ocorrência ou não de outro fato criminoso. Nas palavras da Conselheira:

Sendo o comportamento criminoso uma relação entre a ação do sujeito e o meio que realiza essa ação, seria possível estabelecer graus de periculosidade ou prognóstico de reincidência a partir da análise tão exclusivamente de alguns vetores do comportamento ligados ao sujeito? Seria possível pretender alertar às autoridades da ocorrência de um futuro comportamento criminoso desconsiderando as contingências? A resposta parece ser negativa. Então por que submeter os sujeitos que passam pela prisão a essa medida? Qual sua intencionalidade? Que conceitos são evocados para justificar tal procedimento? (CONSELHO NACIONAL DE POLITICA CRIMINAL E PENITENCIÁRIA, 2008, p. 8 e 9).

Não é por outra razão que o Conselho Federal de Psicologia (CFP) editou a resolução de $n^{\text {o }}$ 0009/2010, que regulamenta a atuação do psicólogo no sistema prisional. Na resolução, vedou a participação de psicólogos na elaboração de laudos criminológicos que tenham por objetivo instruir pedidos de progressão de regime ou livramento condicional ${ }^{4}$. Isso, por reconhecer a ineficiência do exame como instrumento para prever a reincidência, seja pelas condições impróprias em que é realizado seja por seu objetivo de prever condutas sem analisar as várias determinantes que contribuem para a o comportamento criminoso.

Em nota o Conselho Federal de Psicologia esclareceu os motivos que levaram à edição da resolução mencionada:

\begin{abstract}
A Resolução 009/2010 é resultado de debates realizados sobre o uso do exame criminológico para concessão de benefícios legais, como livramento condicional ou progressão de regime. Entende-se que não é possível realizar tal prática sem considerar a eficácia do modelo de privação de liberdade, ou seja, as condições de execução da pena, que são variáveis importantes e que interferem no processo de avaliação. Não é possível concluir o que ocorrerá com aquelas pessoas, considerando apenas as suas características e condições individuais, sem problematizar todo o processo e os elementos oferecidos para a suposta ressocialização ou superação de fatores que o levarão a cometer novos delitos. (...) Ao vedar a realização do exame criminológico pelos psicólogos, os Conselhos de Psicologia têm claro que este exame nunca contribuiu para o desenvolvimento de políticas de continuidade, ou seja, acompanhamento do preso ou atendimento psicológico. Ao contrário, ele leva à substituição de acompanhamento sistemático e contínuo dos indivíduos pela simples rotulação, que pode beneficiar ou prejudicar
\end{abstract}

\footnotetext{
4 Nesse sentido prevê o artigo $4^{\circ}$ da Resolução 0009/2010: "Art. 4 . Em relação à elaboração de docume ntos escritos: a) Conforme indicado nos Art. $6^{\circ}$ e $112^{\circ}$ da Lei $n^{\circ} 10.792 / 2003$ (que alterou a Lei $n^{\circ} 7.210 / 1984$ ), é vedado ao psicólogo que atua nos estabelecimentos prisionais realizar exame criminológico e participar de ações e/ou decisões que envolvam práticas de caráter punitivo e disciplinar, bem como documento escrito oriundo da avaliação psicológica com fins de subsidiar decisão judicial durante a execução da pena do sentenciado. b) O psicólogo, respaldado pela Lei $n^{\circ}$ 10792/2003, em sua atividade no sistema prisional somente deverá realizar atividades avaliativas com vistas à individualização da pena quando do ingresso do apenado no sistema prisional. Quando houver determinação judicial, o psicólogo deve explicitar os limites éticos de sua atuação ao juízo e poderá elaborar uma declaração conforme o Parágrafo Único. Parágrafo Único. A declaração é um documento objetivo, informativo e resumido, com foco na análise contextual da situação vivenciada pelo sujeito na instituição e nos projetos terapêuticos por ele experienciados durante a execução da pena. (BRASIL, 2010, p.3)
} 
os sujeitos, sem que contribua com soluções para os problemas identificados pelos profissionais psicólogos - presentes no comportamento dos indivíduos, mas também no contexto, na sociedade, nas relações em que cada ser está inserido. Ademais, o exame criminológico gera expectativas reducionistas e simplistas quanto à possibilidade de prever o comportamento futuro do preso, visto que o comportamento é fruto de um conjunto amplo e diversificado de determinantes. (...) Pode-se questionar também a forma como são realizados os exames criminológicos, os quais, ainda que não mais previstos em Lei, são solicitados para ser realizados em pouco tempo e em condições impróprias, levando à tomada de decisão em processos de soltura de pessoas que podem não corresponder às condições adequadas para a convivência social. (CONSELHO FEDERAL DE PSICOLOGIA, 2010)

No mesmo sentido, Brito ressalta que "do ponto de vista dos profissionais envolvidos, é quase impossível que o exame tenha aplicação, principalmente pelo diagnóstico que se propõe: prever o futuro". (2013, p. 71)

Ainda que se insista na viabilidade de realização do exame, confrontando com as bases do Estado Democrático de Direito, mostra-se incompatível, vez que se fundamenta no direito penal do autor, em detrimento do fato criminoso praticado.

O exame criminológico mostra-se como representação do direito penal do autor ${ }^{5}$, na medida em que a punição - com a manutenção em regime de cumprimento mais gravoso fundamenta-se na subjetividade do sentenciado e, portanto, desvinculada do fato por ele praticado; pauta-se na culpabilidade do autor em detrimento da culpa pelo fato.

Seja qual for a perspectiva a partir de que se queira fundamentar o direito penal do autor (culpabilidade de autor ou periculosidade), o certo é que um direito que reconheça, mas também que respeite a autonomia moral da pessoa jamais pode penalizar o "ser" de uma pessoa, mas somente o seu agir, já que o direito é uma ordem reguladora de conduta humana. Não se pode penalizar um homem por ser como ele escolheu ser, sem que isso violente a sua esfera de autodeterminação. (ZAFFARONI; PIERANGELI, 2001, p.119-120)

Com o Direito Penal de autor surge o denominado tipo de autor, pelo qual criminaliza-se a personalidade, e não a conduta, com o fim de que não seja preciso esperar o acontecimento do fato criminoso para punição. Tal como ocorre com o exame criminológico avalia-se a personalidade do sujeito e, identificando certa tendência para as práticas criminosas, pune-se com a manutenção em regime mais rigoroso, ainda que o sujeito não tenha efetivamente reincidido ou praticado alguma falta grave.

\footnotetext{
5 O entendimento doutrinário e jurisprudencial dominante acerca da culpabilidade é o da culpabilidade do fato. Francisco de Assis Toledo (1994, p. 235) explica que para essa corrente a censura recai sobre o fato do agente, ou seja, a ação ou omissão que realiza um fato definido como crime. Conforme explica o mesmo autor, há correntes minoritárias que deslocam o juízo de culpabilidade para a culpa do autor. Essa culpabilidade não censura o agente por seu comportamento, mas sim pela sua conduta de vida, seu caráter, sua personalidade. Não se funda no que o agente faz, mas o que ele é. Esse entendimento é conhecido como direito penal do autor, justamente por se fundar no que o agente é, em detrimento do que ele faz.
} 
O que se observa na perícia criminológica é a personalidade do agente que pode indicar uma tendência acentuada para a prática do crime, a chamada periculosidade. Revestese de aparente cientificidade, ocultando o que verdadeiramente representa: um juízo de "futurologia", fundado na culpa do autor, com o fim de neutralizar o indesejável, ainda que sob o pretexto de se garantir os interesses sociais ${ }^{6}$.

Ora, "sob o pretexto de ser uma pessoa "perigosa", o condenado terá negado seus benefícios, em clara contradição com a própria finalidade da pena, que é disponibilizar àquele as condições apropriadas para que conduza a sua vida de forma lícita". (BRITO, 2013, p.77)

Por essa razão, segundo afirma Aury Lopes Jr., "qualquer prognóstico que tenha por mérito "probabilidades" não pode, por si só, justificar a negação de direitos, visto que são hipóteses inverificáveis empiricamente", representando "uma porta aberta ao subjetivismo incontrolável". A avaliação sobre a personalidade de alguém "é inquisitiva, visto estabelece juízos sobre a interioridade do agente. Também é autoritária, devido às concepções naturalistas em relação ao sujeito-autor do fato criminoso". (LOPES JR. 2013, p.626)

Assim, o exame criminológico mostra-se como um exercício de previsão de condutas, pautado em alguns indícios que não têm o condão de serem determinantes da conduta criminosa do agente. E, considerando que não é possível defender a existência da periculosidade como a pré-determinação do indivíduo ao crime, tão pouco a possibilidade de se mensurar essa determinação, o exame criminológico não encontra razão para subsistir pela inexistência de seu próprio objeto.

Ademais, considerando a prática inquisitiva e autoritária, como bem argumentou Lopes Jr., não restam dúvidas quanto ao descompasso da exigência do exame criminológico em um Estado Democrático de Direito.

Ultrapassada a análise do objeto do exame criminológico, passa-se a observar o histórico de alterações legislativas concernentes à esta perícia, para então identificar o fundamento legal no qual se ampara o requerimento de uma perícia criminológica.

\footnotetext{
6 Por seu turno, FRANZ v. LISZT proclamava que se devia castigar o autor antes que o fato cometido por ele, bem como que os juízes deviam expedir sentenças penais indeterminadas cujo cumprimento dependeria em grande medida da personalidade do delinqüente.
} 


\section{O EXAME CRIMinológico NA LEI DE EXECUÇÃo PENAL: AS ALTERAÇÕES LEGISLATIVAS}

A Lei de Execução Penal, em sua redação original, trazia como requisitos para concessão dos benefícios da progressão de regime e livramento condicional, até 2003, o preenchimento de lapso temporal determinado e o mérito do condenado, que, quando necessário, poderia ser confirmado por parecer da Comissão Técnica de Classificação e exame criminológico, conforme demonstrado na transcrição do dispositivo legal:

Art. 112. A pena privativa de liberdade será executada em forma progressiva, com a transferência para regime menos rigoroso, a ser determinada pelo Juiz, quando o preso tiver cumprido ao menos $1 / 6$ (um sexto) da pena no regime anterior e seu mérito indicar a progressão.

Parágrafo único. A decisão será motivada e precedida de parecer da Comissão Técnica de Classificação e do exame criminológico, quando necessário. (grifo nosso) (BRASIL, 2003, p.368)

Da leitura do dispositivo legal, verifica-se o aspecto facultativo indicado pela expressão "quando necessário" presente no parágrafo único do artigo 112 da LEP.

Após a alteração legislativa promovida pela Lei no 10.792 de 2003, o artigo 112 da LEP deixou de prever expressamente a possibilidade de requerimento do exame criminológico, de maneira a exigir como requisito para a progressão de regime apenas o lapso temporal e o atestado de bom comportamento carcerário, elaborado pelo diretor do estabelecimento prisional $^{7}$ :

Art. 112. A pena privativa de liberdade será executada em forma progressiva com a transferência para regime menos rigoroso, a ser determinada pelo juiz, quando o preso tiver cumprido ao menos um sexto da pena no regime anterior e ostentar bom comportamento carcerário, comprovado pelo diretor do estabelecimento, respeitadas as normas que vedam a progressão.

$\S 1^{\circ}$ A decisão será sempre motivada e precedida de manifestação do

Ministério Público e do defensor.

$\S 2^{\circ}$ Idêntico procedimento será adotado na concessão de livramento condicional, indulto e comutação de penas, respeitados os prazos previstos nas normas vigentes. (BRAIL, 2010, p. 1016)

\footnotetext{
7 Carmen Silvia de Moraes Barros defende que a nova redação do art. 112 da LEP não retirou o mérito como um dos requisitos necessários à concessão da progressão de regime ou livramento condicional, mas somente instituiu um critério mais objetivo para sua aferição, qual seja, em vez de exame criminológico, atestado de comportamento carcerário. (BARROS, 2004, p. 181)
} 
Dessa forma, a redação atual do artigo 112 da LEP não menciona o exame criminológico como instrumento de que poderia dispor o magistrado para aferição do requisito subjetivo. Pela nova redação basta o implemento do requisito objetivo e o atestado de bom comportamento carcerário, firmado pelo diretor do estabelecimento prisional, suficiente para aferir o requisito subjetivo.

Considerando a ausência de previsão legal, atualmente, a exigência do exame criminológico fundamenta-se na súmula vinculante número 26, do STF:

Súmula Vinculante 26: Para efeito de progressão de regime no cumprimento de pena por crime hediondo, ou equiparado, o juízo da execução observará a inconstitucionalidade do art. 2o da Lei n. 8.072, de 25 de julho de 1990, sem prejuízo de avaliar se o condenado preenche, ou não, os requisitos objetivos e subjetivos do benefício, podendo determinar, para tal fim, de modo fundamentado, a realização de exame criminológico. (BRASIL, 2009)

Importa constatar que a súmula editada em 2009 ousou contrariar a vontade legislativa de suprimir esse requisito e cuidou de restabelecer a facultatividade da exigência do exame. ${ }^{8}$

Não foi por outra razão que o ministro Marco Aurélio, quando da votação da proposta da súmula vinculante número 26 , manifestou-se contrariamente à sua edição ao argumento de que se a Lei $\mathrm{n}^{\circ} 10.792$ de 2003 derrogou o texto anterior da LEP que previa o exame criminológico; aprovar a súmula seria reintroduzir exigência prejudicial ao réu:

\begin{abstract}
Mantém-se a exigência do exame criminológico? Restabelecemos, portanto, ignorando a derrogação ocorrida, o texto anterior. Antecipamo-nos, portanto, à aprovação do projeto que está em curso no Congresso? Apenas quero entender. (...) Penso que se reintroduz no cenário normativo - já que o verbete vinculante tem força erga omnes, só não obrigando o Congresso Nacional -, exigência prejudicial ao réu. Volta a valer o texto primitivo derrogado pela lei que mencionei, a Lei $\mathrm{n}^{\mathrm{o}}$ 10.792/03. A derrogação, para mim, mostra-se, no caso, muito clara. Por quê? Porque antes havia o parágrafo único com a seguinte redação: "a decisão será motivada e precedida de parecer da comissão técnica de classificação e do exame criminológico". Esse texto foi expungido, ou seja, tendo em conta a realidade brasileira, (...) esse exame já se mostrava senão inócuo - quanto ao conteúdo de duvidosa propriedade -, inviável, porque oitenta mil presos aguardavam, havendo alcançado tempo para a progressão, o famigerado exame. Recordo, a imprensa veiculou a existência de trabalho visando, justamente, a dar àqueles que estão sob custódia do Estado tratamento digno, tratamento previsto na própria Constituição. (BRASIL, 2010)
\end{abstract}

\footnotetext{
8 A esse respeito, segue a eloquente crítica do autor Renato Flávio Marcão: "indeferir pedido de progressão com base em apontamento do laudo criminológico, se o executado cumpriu um sexto da pena no regime atual e juntou atestado de boa conduta carcerária, nos termos do art. 112 da Lei de Execução Penal, corresponde a indeferir pedido com base em requisito não exigido. É preciso enxergar a verdadeira intenção do legislador e admitir a mudança. A lei não muda para ficar tudo como estava". (MARCÃO, 2007, p.14)
} 
Não obstante o brado do ministro, a súmula foi aprovada com registro de apenas esta oposição. Assim, atualmente a exigência do exame criminológico encontra respaldo na súmula vinculante número 26 do STF que restabeleceu a redação original do artigo 112 da LEP, ao arrepio da vontade legislativa que o havia alterado para suprimir o referido requisito subjetivo. A possível razão da insistência jurisprudencial, ainda que não declarada, passa a ser analisada a seguir.

\section{A EXIGÊNCIA DO EXAME CRIMINOLÓgICO COMO ESTRATÉGIA DE BIOPODER}

Ao analisar o exame criminológico, necessário se faz uma reflexão desse tema em conjunto com os estudos acerca do chamado „biopoder“e desenvolvidos por Michel Foucault. Isso porque a exigência do exame criminológico tem o objetivo precípuo de servir como mecanismo de segurança para a população, uma vez que visa evitar que o sentenciado retorne ao convívio social quando ainda apresenta elevada periculosidade. Por seu turno, a segurança que se pretende assegurar pode ser entendida, a partir de uma apreciação foucaltiana, como dispositivo que sustenta o conceito denominado biopolítica ou biopoder.

Segundo o autor, o biopoder seria uma "série de fenômenos que me parece bastante importante, a saber, o conjunto dos mecanismos pelos quais aquilo que, na espécie humana, constitui suas características biológicas fundamentais vai poder entrar numa política, numa estratégia política, numa estratégia geral de poder". (FOUCAULT, 2008, p. 3)

No biopoder foucaltiano, o poder é concebido não mais a partir de uma concepção do antigo direito soberano, que fazia morrer e deixava viver, mas de um poder que funciona de maneira inversa, que faz viver ou deixa morrer. Em outros termos: "enquanto o poder soberano expõe a vida à morte, o biopoder, em contrapartida, se exerce de maneira positiva sobre a vida, busca administrar e aumentar suas forças, para distribuí-las em um campo de valor e utilidade." (CASTRO, 2014, p.103).

Assim, o biopoder é o "poder sobre a vida", que utiliza fenômenos próprios à vida (e.g. natalidade, sexualidade, epidemias) como meio de administração econômica de populações mediante políticas públicas, edição de leis, etc. Nesse contexto, o Estado utiliza instrumentos que permitem gerir a vida da população a partir de uma lógica biopolítica. 
Em seus estudos, Foucault também se ateve a outra consequência do desenvolvimento do biopoder, que seria a importância crescente assumida pela atuação da norma, à custa do ordenamento jurídico. (FOUCAULT, 1984).

Nesse contexto, a prisão também funcionaria como uma espécie de controle social punitivo institucionalizado (ZAFFARONI; PIERANGELI, 2001, p.69) a reger mecanismos que tornam possível a gestão da vida a partir da lógica biopolítica de segregação e neutralização dos indesejáveis. Tal lógica de segregação é reafirmada até mesmo pelas leis que, nesse contexto, "são os fios de tecelagem (rede) dessa burocracia (Weber) que deve ser continuadamente ampliada de modo seletivo para pescar os melhores e descartar o lixo social." (LEAL, 2010, p.121)

Conforme bem explica Zaffaroni e Perangeli, há uma clara demonstração de que não somos todos igualmente „vulneráveis ${ }^{\text {ee }}$ ao sistema penal, que costuma orientar-se por „estereótipose que recolhem os caracteres dos setores marginalizados. A criminalização gera, a seu turno, um fenômeno de rejeição do etiquetado como também daquele que se solidariza ou contata com ele, de forma que a segregação se mantém na sociedade livre. A posterior perseguição por parte das autoridades com rol de suspeitos permanentes, incrementa a estigmatização social do criminalizado. (ZAFFARONI; PIERANGELI. 2001, p. 73)

O que se questiona na biopolítica moderna são os critérios de eleição dos estigmas que devem ser apartados do meio social bem como os subterfúgios de que se vale a autoridade para encobrir as práticas segregacionistas com uma aparência de legalidade; o que faz com que o senso comum absorva com naturalidade as políticas públicas implementadas ao argumento de se preservar o bem estar coletivo.

Com a exigência do exame criminológico restabelecida pelo STF, vê-se que os mecanismos de controle e dominação ultrapassam a esfera legislativa e alcançam os órgãos jurisdicionais, que passam a representar um Estado preocupado com o bem-estar coletivo, a quem "caberia impor seu conhecimento e senso de justiça para corrigir as agruras dos desequilíbrios sociais, ainda que tal implicasse a inobservância dos textos legais". (LEAL, 2002, p.28).

O Estado, através de suas instituições dirigentes ${ }^{9}$, passa a ser o grande mentor da vida e do bem-estar, tornando-se o único foro de atividade política, a que se deve inteira fidelidade: a sociedade está estatizada, absorvida pelo Estado. Portanto, os problemas e as

\footnotetext{
9 Expressão utilizada por Muniz Sodré na obra "Sociedade, mídia e violência".
} 
políticas sociais se fundem aos problemas e políticas do Estado ${ }^{10}$. Os órgãos atrelados ao Estado funcionam como agentes capazes de restabelecer a ordem em conformidade com o que interessa à política pública vigente.

Quando o STF restabelece a exigência do exame criminológico, criando um requisito que condiciona a fruição do benefício da progressão de regime, acaba por permitir a ingerência do poder político na determinação da política pública de encarceramento. Mostrase como gestor da vida, determinando aquele que deve permanecer neutralizado por ser quem é, ou seja, baseando-se na personalidade do agente. ${ }^{11}$

Nessa senda, os encarcerados apresentam-se como não-sujeitos, "como seres carentes dos direitos próprios, do ser humano e, portanto, como nua vida. A eles se aplica esse modo de política chamado biopolítica, porque vela-se nela tudo o que essa atividade humana coletiva possa ter de vontade ou racionalidade (...)." (REYES MATE, 2005, p. 94) Com a destituição da sua condição de sujeito, passa-se a admitir a ingerência estatal em sua vida e sobre seus direitos, em consonância com o que preconiza a política pública vigente. ${ }^{12}$

Assim, a exigência do exame criminológico funciona como mecanismo de gestão da vida e, considerando que o objeto do exame criminológico é a periculosidade, a aferição de requisito alcança alto nível de subjetividade, eis que, conforme mencionado, não é possível prever o comportamento humano. O laudo criminológico, com a subjetividade de avaliação da personalidade do condenado que lhe é próprio, permite o controle daquele que permanece no cárcere ou retorna à liberdade ou semiliberdade, de acordo com o que determina a estratégia das políticas públicas vigentes.

Há, pois, uma estratégia amparada em uma aparente cientificidade, resultante da ocultação das formas de dominação política, que conta com a correta eleição dos mecanismos de poder sob a justificativa de se proteger os interesses sociais

\footnotetext{
10 Tradução livre do original: "El Estado se vuelve el único foro de actividad política, al que se debe entera fidelidad: la sociedad está "estatizada", tragada por el Estado. Por lo tanto los problemas y las políticas sociales se disuelven em problemas y políticas de Estado". (DAMASKA, 2000, p. 141)

$11 \mathrm{Na}$ biopolítica moderna, "soberano é aquele que decide sobre o valor ou sobre o desvalor da vida enquanto tal. A vida, que, com as declarações dos direitos, tinha sido investida como tal do princípio da soberania, torna -se agora ela mesma o local de uma decisão soberana." (AGAMBEM, 2002, p. 149)

12 A esse respeito, Barros alerta que "dar por prevalentes os interesses sociais na execução penal é negar vigência ao princípio da individualização da pena e às garantias constitucionais e usar o preso para dar satisfação à sociedade, ignorando sua individualidade e dignidade. (...) individualizar a pena na execução penal é ter em vista o sentenciado e seu necessário retorno ao convívio social e ao mesmo tempo impedir que sua individualidade sirva de exemplo para alcançar fins que não lhe dizem respeito (por exemplo, interesses sociais em determinado momento). Assim não fosse, tampouco se poderia falar em respeito à dignidade do preso. (BARROS, 2004, p. 182 e 183)
} 


\section{CONSIDERAÇÕES FINAIS}

O exame criminológico é uma perícia com a qual se pretende avaliar o grau de periculosidade do agente no momento da concessão da progressão de regime, já na fase de execução da pena. Mostra-se como um complemento ao requisito subjetivo do bom comportamento carcerário, atestado pelo diretor do estabelecimento prisional.

Não obstante a supressão da facultatividade de sua exigência pela lei 10.792/03, atualmente é possível a determinação da realização do exame em razão da súmula vinculante número 26 editada em 2009 pelo STF.

Em atendimento à biopolítica vigente, busca-se manter o encarceramento do indesejável ao argumento de uma suposta preservação da segurança social. Mostra-se como um mecanismo de gestão da vida em consonância com a política pública de segregação.

Dada a subjetividade da confecção do laudo criminológico torna-se incerta a concessão dos benefícios da progressão de regime ou livramento condicional, a depender de exame de previsão de condutas alheio a qualquer controle de legitimidade por parte do sentenciado.

Se o objetivo do exame é neutralizar o apenado com sua manutenção em regime mais rigoroso, dificultando o gozo do sistema progressivo de penas, seria mais coerente o aumento do requisito objetivo necessário ao alcance dos benefícios próprios da execução penal. Isso porque, permitiria a fiscalidade do implemento do requisito pelo sentenciado, tornando certa a pena a ser cumprida para o ingresso nos regimes semiaberto, aberto ou mesmo a liberdade condicional, em vez de estar condicionado a um juízo de previsão de condutas sabidamente imprevisíveis.

Porém, isso não ocorre porque faz parte da ocultação das formas de exercício do biopoder, a velada ingerência da vida pelo poder estatal. E, uma vez eliminado esse poder de gestão da vida pela lei 10.792/03, o Estado cuidou de restabelecê-lo, agora por meio de outra instituição dirigente: o STF.

Diante do exposto conclui-se que a exigência do exame criminológico permite segregação dos indesejáveis, funcionando como mecanismo de dispositivo de segurança, ou seja, mostra-se como mecanismo de biopoder do Estado, capaz de gerir a vida segundo a política pública vigente. 


\section{REFERÊNCIAS BIBLIOGRÁFICAS}

AGAMBEN, Giorgio. Homo Sacer: o poder soberano e a vida nua I. Trad. de Henrique Burigo. Belo Horizonte: UFMG, 2002.

BARROS, Carmen Silvia de Moraes. As modificações introduzidas nos arts. $6^{\circ}$ e 112 da LEP pela Lei 10.792/2003 e a jurisdicionalização e a individualização da pena na execução penal. Revista brasileira de ciências criminais, São Paulo, Ano 12, n. 48, p.179-193, mai-jun. 2004.

BRASIL. Exposição de Motivos 213, de 9 de maio de 1983. Exposição de motivos da LEP. In: Código de processo penal. 8.ed. São Paulo: Revista dos Tribunais, 2003, p.335 - 354.

BRASIL. Lei de Execução Penal (1984). Lei de execução penal. Disponível em: <http://www.planalto.gov.br/ccivil_03/leis/17210.htm> Acesso em: 13 fev. 2015.

BRASIL. Supremo Tribunal Federal. Súmula vinculante número 26. Para efeitos de progressão de regime no cumprimento de pena por crime hediondo, ou equiparado, o juízo da execução observará a inconstitucionalidade do art. $2^{\circ}$ da Lei 8072, de 25 de julho de 1990, sem prejuízo de avaliar se o condenado preenche, ou não, os requisitos objetivos e subjetivos do benefício, podendo determinar, para tal fim, de modo fundamentado, a realização de exame criminológico. Diário de Justiça da União, Brasília, 23 de dezembro de 2009. Seção

Plenária. p.1

BRASIL, Supremo Tribunal Federal. Proposta de súmula vinculante 30, Distrito Federal. Voto do Ministro Marco Aurélio. Disponível em <http://www.stf.jus. br/arq uivo/cms/jurisprudenciaSumulaVinculante/anexo/PSV_30.pdf> Acesso em: 07 mar. 2015.

BRITO, Alexis Couto de. Execução Penal. 3ed. São Paulo: Revista dos Tribunais, 2013

CARVALHO, Salo de. O papel da perícia psicológica na execução penal. Psicologia Jurídica no Brasil, Rio de Janeiro, 2.ed. Rio de Janeiro: NAU, 2009, p. 141 - 155.

CASTRO, Edgardo. Introdução a Foucault. Belo Horizonte: Autêntica, 2014. CONSELHO FEDERAL DE PSICOLOGIA. Resolução n. 009/10. Regulamenta a atuação do psicólogo no sistema prisional. Disponível em: <http://www.crpsp.org.br/portal/orientacao/resolucoes_cfp/fr_cfp_009-10.aspx > Acesso em: 14 de mar. 2015.

CONSELHO FEDERAL DE PSICOLOGIA. Nota sobre a Resolução CFP que, ao regulamentar a atuação do psicólogo no sistema prisional, impede a realização do exame criminológico pela categoria. POL, 2010. Disponível em: < http://site.cfp.org.br/nota-sobrea-resoluo-cfp-que-ao-regulamentar-a-atuao-do-psiclogo-no-sistema-prisional-impede-arealizao-do-exame-criminolgico-pela-categoria/> Acesso em: 19 mar. 2015. 
CONSELHO FEDERAL DE PSICOLOGIA. Moção contra o exame criminológico. Disponível em: <http://www.crprj.org.br/documentos/2009-mocao-contra-examecriminologico.pdf> Acesso em: 19 mar. 2015.

DAMASKA, Mirjan. Las caras de la justicia y el poder del Estado: análisis comparado del proceso legal. Santiago: Editorial Jurídica de Chile, 2000.

CONSELHO NACIONAL DE POLÍTICA CRIMINAL E PENITENCIÁRIA. Parecer do CNPCP sobre exame criminológico para progressão de regime. Disponível em: <http://portal.mj.gov.br/data/Pages/MJ9F1AD397ITEMID2D0D9AD3507E4A849A6385DC6 AD105D5PTBRIE.htm > Acesso em: 06 mar. 2015

FOUCAULT, Michel. Vontade de saber. $8^{\text {a }}$ ed. Rio de Janeiro: Graal, 1985.

FOUCAULT, Michel. Segurança, território, população: curso dado no Collège de France (1977-1978). Trad. Eduardo Brandão. Revisão da Tradução: Claudia Berliner. Col. Tópicos. São Paulo: Martins Fontes, 2008.

KOLKER, Tania. A atuação dos psicólogos no sistema penal. Psicologia Jurídica no Brasil, Rio de Janeiro, 2.ed. Rio de Janeiro: NAU, 2009, p. 157 - 159.

LEAL, André Cordeiro. O contraditório e a fundamentação das decisões no direito processual democrático. Belo Horizonte: Mandamentos. 2002.

LEAL, Rosemiro Pereira. Processo como teoria da lei democrática. Belo Horizonte: Fórum, 2010.

LOPES JR., Aury. Direito Processual Penal. 10. Ed. São Paulo: Saraiva, 2013. MARCÃO, Renato Flávio. Curso de Execução Penal. 4. ed. São Paulo: Saraiva, 2007. OLIVEIRA, Edmundo. $O$ delinquente por tendência. $1^{a}$ ed. Rio de Janeiro: Forense, 1980.

PASTORAL CARCERÁRIA NACIONAL - CNBB. Repúdio à re-introdução do parecer da Comissão Técnica de Classificação e do exame criminológico. Disponível em: <http://www.crprj.org.br/documentos/2009-documento-cnbb-exame-criminologico.pdf> Acesso em 12 mar. 2010

REYES MATE, Manuel. Memórias de Auschwitz: atualidade e política. Trad. de Antônio Sidekum. São Leopoldo: Nova Harmonia, 2005.

SODRÉ, Muniz. Sociedade, mídia e violência. 2 ed. Porto Alegre: Sulina: Edipucrs, 2006.

TOLEDO, Francisco de Assis. Princípios Básicos de Direito Penal. 5 ed. São Paulo: Saraiva, 1994.

ZAFFARONI, Eugenio Raúl; PIERANGELI, José Henrique. Manual de direito penal brasileiro: parte geral. 3. ed. São Paulo: Revista dos Tribunais, 2001. 